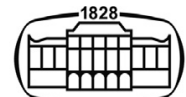

AKADÉMIAI KIADÓ

Journal of Behavioral Addictions

10 (2021) 2, 234-243

DOI:

$10.1556 / 2006.2021 .00022$

(c) 2021 The Author(s)

\section{FULL-LENGTH REPORT}

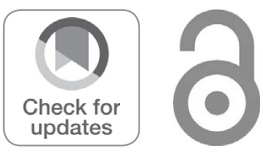

\title{
Multidimensional family therapy reduces problematic gaming in adolescents: A randomised controlled trial
}

\author{
PHILIP NIELSEN ${ }^{1,2 *}$ (1), MAXWELL CHRISTENSEN ${ }^{3}$, \\ CRAIG HENDERSON ${ }^{3}$, HOWARD A LIDDLE ${ }^{4}$, \\ MARINA CROQUETTE-KROKAR ${ }^{1}$, NICOLAS FAVEZ ${ }^{2}$ and \\ HENK RIGTER ${ }^{5}$
}

\author{
${ }^{1}$ Fondation Phénix, Geneva, Switzerland \\ ${ }^{2}$ Unité de psychologie clinique des relations interpersonnelles, FPSE, University of Geneva, Geneva, \\ Switzerland \\ ${ }^{3}$ Department of Psychology and Philosophy, Sam Houston State University, Huntsville, TX, USA \\ ${ }^{4}$ Departments of Public Health Sciences and Psychology, University of Miami Miller School of \\ Medicine, Miami, USA \\ ${ }^{5}$ Department of Child and Adolescent Psychiatry, Leiden University Medical Centre (LUMC), \\ Leiden, the Netherlands
}

Received: September 30, 2020 • Revised manuscript received: December 6, 2020 • Accepted: March 23, 2021

Published online: April 26, 2021

\begin{abstract}
Background and aims: Social variables including parental and family factors may serve as risk factors for Internet Gaming Disorder (IGD) in adolescents. An IGD treatment programme should address these factors. We assessed two family therapies - multidimensional family therapy (MDFT) and family therapy as usual (FTAU) - on their impact on the prevalence of IGD and IGD symptoms. Methods: Eligible for this randomised controlled trial comparing MDFT $(N=12)$ with FTAU $(N=30)$ were adolescents of 12-19 years old meeting at least 5 of the 9 DSM-5 IGD criteria and with at least one parent willing to participate in the study. The youths were recruited from the Centre Phénix-Mail, which offers outpatient adolescent addiction care in Geneva. Assessments occurred at baseline and 6 and 12 months. Results: Both family therapies decreased the prevalence of IGD across the one-year period. Both therapies also lowered the number of IGD criteria met, with MDFT outperforming FTAU. There was no effect on the amount of time spent on gaming. At baseline, parents judged their child's gaming problems to be important whereas the adolescents thought these problems were minimal. This discrepancy in judgment diminished across the study period as parents became milder in rating problem severity. MDFT better retained families in treatment than FTAU. Discussion and Conclusions: Family therapy, especially MDFT, was effective in treating adolescent IGD. Improvements in family relationships may contribute to the treatment success. Our findings are promising but need to be replicated in larger study. Trial registration number: ISRCTN 11142726.
\end{abstract}

\section{KEYWORDS}

internet gaming disorder, adolescent, multidimensional family therapy, randomised controlled trial

\section{INTRODUCTION}

${ }^{*}$ Corresponding author.

For most gamers, Internet gaming is a passion. However, gaming may become problematic if it interferes with personal goals, social life, school or work (Griffiths et al., 2016; King, Wolfling, \& Potenza, 2020; Peeters, Koning, Lemmens, \& van den Eijnden, 2019). The WHO's ICD-11 classification system defines 'Gaming disorder' as a pattern of offline or online gaming behaviour that is continued despite resultant harm (WHO, 2018). 
The Diagnostic and Statistical Manual of Mental Disorders, 5 th edition (DSM-5) has a provisional entry titled 'Internet Gaming Disorder' (IGD), to be established by means of nine criteria (APA, 2013). In studies using DSM-5 based screening tools, the prevalence of IGD in adolescents ranged from 1.2 to $5.9 \%$ (Sugaya, Shirasaka, Takahashi, \& Kanda, 2019). This is not a high rate, yet IGD treatment need may be sizable due to the large scale at which Internet games are being played.

The IGD treatment literature base is small. Quite a few treatment studies were flawed. For instance, out of 30 studies selected for a systematic review, 11 lacked follow-up assessments beyond the treatment period and 11 were not designed as randomised controlled trials (King et al., 2017). To date, the most often tested treatment is cognitivebehavioural therapy (CBT). CBT may reduce IGD symptoms, when assessed at the end of treatment, but there is no evidence that this effect is durable for longer periods of time (Stevens, King, Dorstyn, \& Delfabbro, 2019; Zajac, Ginley, \& Chang, 2020).

IGD in adolescents may not only be linked to intrapersonal characteristics of the youth - the target of CBT - but also to social variables including parental and family factors (Nielsen, Favez, Liddle, \& Rigter, 2019; Nielsen, Favez, \& Rigter, 2020). Reviewers of the treatment literature (Zajac et al., 2020) found just one study of a family-based intervention targeting IGD. This intervention consisted of five sessions focused on improving family cohesion. Only 15 families were included; there was no control group and no follow-up assessment beyond the brief treatment period (Han, Kim, Lee, \& Renshaw, 2012).

Several family therapies score well as treatments for adolescents with diverse problem behaviour (Baldwin, Christian, Berkeljon, \& Shadish, 2012; Davis et al., 2015; van der Pol et al., 2017). One of these treatment programmes is multidimensional family therapy (MDFT). MDFT outperforms a variety of therapeutic approaches, including less intensive family-based approaches and CBT, in reducing substance use disorders (SUD), delinquency and comorbidity and improving family harmony and school performance (Liddle, 2016; van der Pol et al., 2017). This therapy targets risk and protective factors from developmentally influential social domains for adolescents, such as family, friends, and school (Liddle, 2016; Liddle \& Rigter, 2013).

Because of its multi-system nature, we assumed that MDFT could be beneficial for adolescents with IGD. MDFT clinicians from Miami, Geneva and Paris adapted MDFT for IGD treatment purposes (Bonnaire, Liddle, Har, Nielsen, \& Phan, 2019; Bonnaire, Liddle, Har, \& Phan, 2020). Next, we designed a randomised controlled trial comparing the effectiveness of IGD-adapted MDFT in reducing IGD in adolescents as compared with family therapy as usual (FTAU). We hypothesized that family therapy would reduce the prevalence of IGD from $100 \%$ at baseline to significantly lower values at 6- and 12-months follow-up, with MDFT outperforming FTAU.

\section{METHODS}

\section{Study design}

This study was a randomised controlled effectiveness trial with an open-label, parallel group design. The trial was registered as ISRCTN 11142726 on 22 September 2016 by WHO's International Clinical Trials Registry Platform.

The study participants were recruited from the adolescents who were regularly referred for outpatient treatment to Centre Phénix-Mail. Referral sources were mainly parents (38.1\%), schools (28.6\%) and treatment centres (23.8\%). Eligible were males and females between 12 and 19 years of age meeting at least 5 of the 9 DSM-5 IGD criteria.

We wanted the trial to be relevant for daily practice, and therefore applied only a few exclusion criteria. An adolescent was excluded if his or her psychological functioning was impaired to the point of needing inpatient treatment as judged by the trial's medical supervisor. We did not enrol adolescents who were already receiving psychotherapy elsewhere. Adolescents were also excluded if they or their parents did not speak French or English.

Of a total of 71 adolescents assessed for the study, 42 were included and 29 were excluded. Main reasons for exclusion were meeting less than 5 IGD symptoms, and lack of informed consent (Fig. 1).

\section{Recruitment process and randomisation}

Recruitment ran from December 2016 to December 2018. Each new case was screened for possible IGD, and, if identified as such, was invited with his/her parent(s) for a clinical interview with the study's medical supervisor, a psychiatrist. If the psychiatrist deemed the family to be potentially eligible, she asked the adolescent to complete Petry's IGD scale (see below) out of the parents' sight. If the adolescent's score verified the presence of IGD, the psychiatrist explained the study to the family members and gave them study information and informed consent materials to take home to read and sign if willing to participate. One week later, the consenting families attended a meeting with the research assistant for the baseline assessment and for random allocation to MDFT or FTAU, in a proportion of 1:3 (the centre had three times more capacity to deliver FTAU than MDFT). Allocation was concealed (computer-generated). Cases were coded to warrant anonymity.

\section{Treatments}

Treatment started within one month of the baseline assessment and lasted for approximately 6 months. MDFT ( 3 therapists) and FTAU (4) were delivered by psychologists and psychiatrists with similar long-term experience in treating youth with problem behaviour.

MDFT. MDFT is a treatment programme for adolescents displaying problem behaviour.

The term 'multidimensional' reflects that each major domain in the life of an adolescent is thought to contribute 


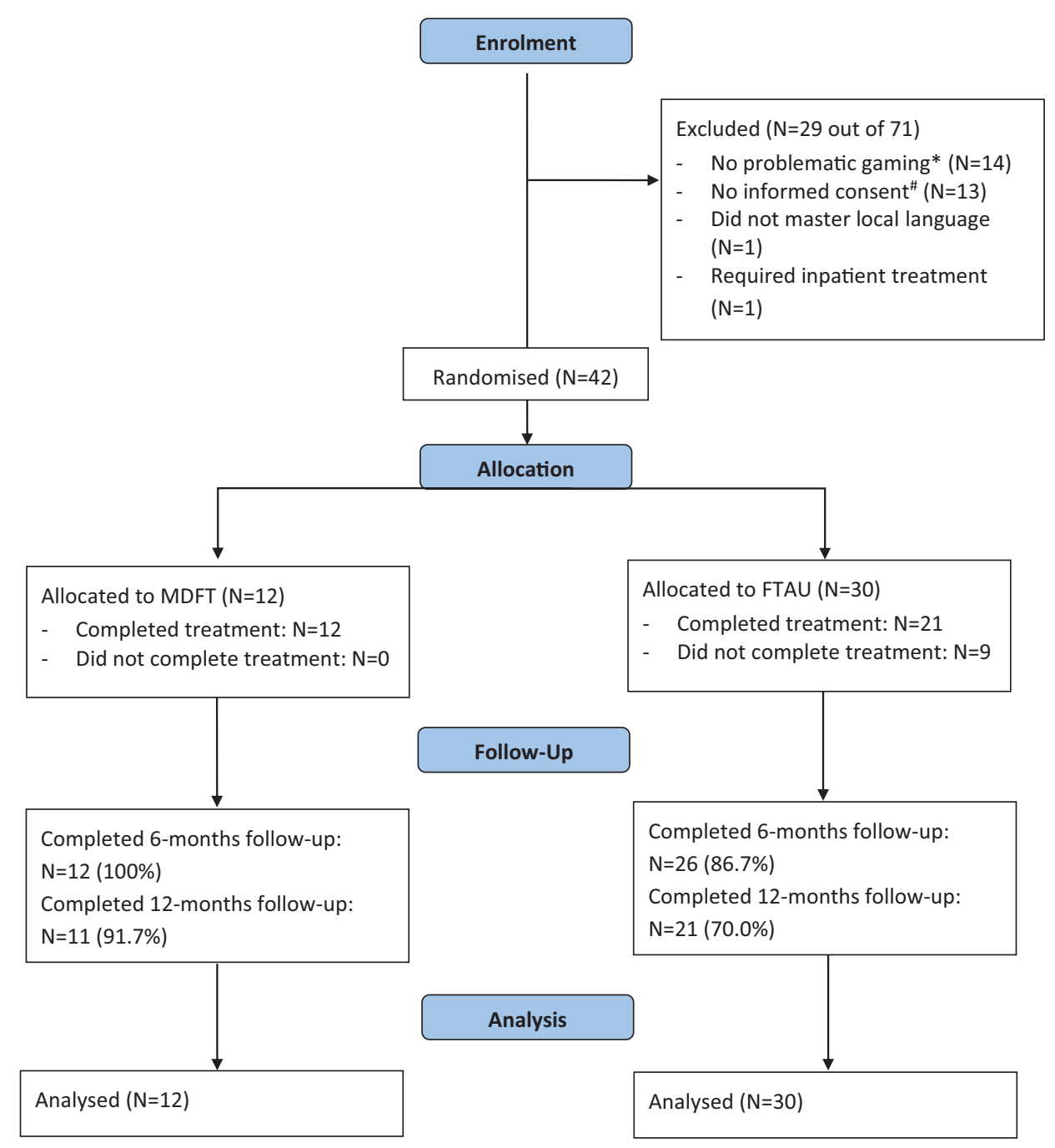

Fig. 1. Trial flow diagram: number of adolescents per stage. MDFT $=$ multidimensional family therapy. FTAU $=$ family therapy as usual. * As assessed with Petry's DSM-5-based IGD scale. " Informed consent could be refused by the adolescent and/or the parents at various times, from the moment they were invited for the meeting with the medical director, during that meeting before or after the Petry IGD scale had been administered, and at any moment thereafter until randomisation

to his or her behavioural problems, through risk and protective factors. The life domains considered in MDFT include the youth him- or herself, parents, family, friends and peers, school and work, and leisure time.

MDFT consists of three stages. In the first one, treatment motivation is enhanced, multiple therapeutic alliances are forged, and the treatment plan is drafted. In stage 2, interventions targeting the youth, the parents, and possibly others are carried out. These include improving family communication and relationships, strengthening competent parental educational practices, and helping the adolescents develop more adaptive and prosocial coping skills. Stage 3 involves developing a relapse prevention plan and sealing off the treatment.

The MDFT manual from earlier trials (Liddle, 2002) was also used in the current study, but with adaptations to better reflect IGD treatment goals. The objective of MDFT in IGD is not to achieve abstinence (stopping with gaming fully) but rather to free the adolescent from gaming associated harm and to achieve healthier, unproblematic gaming.
MDFT entails two sessions per week on average, and the therapist conducts sessions with the adolescent alone, the parents, and the family (family sessions: adolescent plus parents).

Family therapy as usual. We compared MDFT with the other family therapy offered by Phénix-Mail (FTAU). FTAU comprises best-practice procedures as applied by systemsoriented therapists in family therapy in the French-speaking part of Switzerland. The methods applied are eclectic, combining elements from structural-strategic, narrative and solution focused family therapy.

FTAU strives to enhance family communication skills. There are no distinct treatment stages. Alliance building and improving relations and communication within the family are common targets of treatment. As in MDFT, sessions are held with the adolescent alone, the parents alone, and with the family. FTAU was delivered in one session per week, as usual, resulting in a lower treatment dosage than for MDFT. 
Treatment integrity. MDFT sessions were recorded on video for therapist certification and re-certification purposes. A certified MDFT trainer, not affiliated with the study, reviewed the sessions for therapist competence and adherence, using standard procedures (Rowe et al., 2013). In all cases, MDFT fidelity criteria were met. FTAU, not being a manualised approach, was not rated for adherence but benefitted from monthly supervision sessions delivered by a senior family therapist and trainer.

\section{Assessments and measures}

Assessments were conducted at baseline and 6 months and 12 months later. Table 1 lists the measures used. Personal and demographic data was collected, at baseline and 12 months follow-up, with the Adolescent Interview and Parent Interview, as delivered in earlier MDFT research (Rigter et al., 2010, 2013) but adapted for IGD. Topics included demographics, problem behaviour, parenting practices, school and work problems, peers, and leisure time activities.

To establish IGD, we selected a tool that covered all nine DSM-5 criteria (King, Chamberlain, et al., 2020). We opted for the French version of Petry's DSM-5-based IGD scale (Petry et al., 2014), which was tested in a French population and found to have a one-dimensional (single-factor) structure. Its internal consistency was satisfactory (Cronbach's $\alpha=0.82$ ). The scale performed well in tests of criterion validity and convergent validity (Sarda, Begue, Bry, \& Gentile, 2016). The Petry scale is a self-report questionnaire, to be completed by the adolescent. It contains nine questions, one for each DSM-5 IGD symptom, with the response options being 'Yes' and 'No'.

To record the frequency of gaming, we applied the wellestablished Time-Line Follow-Back (TLFB) method (Barrett, Slesnick, Brody, Turner, \& Peterson, 2001; Robinson, Sobell, Sobell, \& Leo, 2014), with the term 'substance use' replaced by 'gaming'. The TLFB is a calendar-type form allowing the

Table 1. Measures per round of assessments

\begin{tabular}{lccc}
\hline & \multicolumn{3}{c}{ Assessment } \\
\cline { 2 - 4 } Measure & Baseline & $\begin{array}{c}\text { Follow-up, } 6 \\
\text { months }\end{array}$ & $\begin{array}{c}\text { Follow-up, } \\
12 \text { months }\end{array}$ \\
\hline Adolescent Interview & $\mathrm{x}$ & & $\mathrm{x}$ \\
Parent Interview & $\mathrm{x}$ & $\mathrm{x}$ & $\mathrm{x}$ \\
Petry's IGD scale & $\mathrm{x}$ & $\mathrm{x}$ & $\mathrm{x}$ \\
TLFB & $\mathrm{x}$ & $\mathrm{x}$ & $\mathrm{x}$ \\
Gaming section, ASC & $\mathrm{x}$ & & $\mathrm{x}$ \\
$\quad$ T-ASI, adolescent & & $\mathrm{x}$ & \\
Gaming section, ASC & $\mathrm{x}$ & $\mathrm{x}$ & \\
$\quad$ T-ASI, parent & & $\mathrm{x}$ & \\
Treatment satisfaction & & & \\
$\quad$ adolescent & & & \\
Treatment satisfaction & & & \\
parent & & & \\
\hline
\end{tabular}

ASC T-ASI $=$ the Abbreviated Self Completion Teen-Addiction Severity Index 1. IGD = Internet Gaming Disorder. Not shown: measures of comorbidity (to be reported elsewhere). adolescent to note down on which days he or she played games and for how long. The timeframe chosen, guided by validity data (Robinson et al., 2014), was 90 days preceding the assessment.

Using the Abbreviated Self Completion Teen-Addiction Severity Index (Goorden, van der Schee, Hendriks, \& Hakkaart-van Roijen, 2016; Reckers-Droog et al., 2020), we assessed the adolescent's quality of life for six topics or domains. We report here on one topic, i.e., gaming issues. The adolescent was asked if he or she experienced any problems with gaming, with response options varying from 0 (no problems) to 4 (very big problems). The parents used the same 5-point scale to give their view on the severity of their child's problems.

\section{Statistical analyses}

We analysed continuous variables with the t-test comparison of means. For categorical variables, we used the $\chi^{2}$ test for independent samples, to be replaced by the Fisher Exact Test when cell frequency was below the minimum number of expected observations assumed under a $\chi^{2}$ distribution.

To compare differences between treatment groups across time, we used mixed-effect analysis of variance (ANOVA) tests. Significant multivariate effects were assessed with Wilk's Lambda and followed by interpretation of univariate main effects and interactions as appropriate. Due to the within-subjects nature of these procedures, participants were only included if they participated in all assessment waves.

Missing data. There were few missing data among individuals who participated at each study timepoint $(<5 \%$ per item). Missing data were handled using pairwise deletion methods to preserve sample size, and scale scores were calculated using person-mean imputation. To confirm the thus obtained results, we conducted supplemental intent-totreat analyses by means of multiple imputation (MI). MI produces unbiased parameter estimates when data are missing (Schafer \& Graham, 2002). We carried out MI using algorithms in the SPSS (version 25) Missing Value Analysis package through 20 replications of the imputed data. We elected against presenting the MI method as our primary analysis due to the limitation of MI as implemented in SPSS, which precludes pooling replication results, presumably due to complications in pooling error variance for the $F$ statistic across replications (Schafer \& Graham, 2002). We present the MI analyses results as supplementary material to this paper and provide an averaged $F$ statistic combined across replications in the text. In all cases, the MI-based results confirmed the results reported in the text.

\section{Ethics}

The study procedures were carried out in accordance with the Declaration of Helsinki. The Institutional Review Board of the Commission Cantonale d'Ethique de la Recherche, Geneva canton approved the study. All subjects were informed about the study and all provided informed consent. Parental consent was sought for those younger than 18 years of age. 


\section{RESULTS}

\section{General characteristics of the study participants}

Averaged across groups, the adolescents were 14.9 years of age. All but one were boys. In $47.6 \%$ of cases, the parents were separated or divorced. Except for three, all adolescents were enrolled in school, mostly at a high $(20.5 \%)$ or middle (74.4\%) secondary school (Table 2).

At baseline, the adolescents rarely reported problem behaviour that was not related to gaming. The vast majority (88.1\%) never drank alcohol, and the others did so occasionally ( $\leq 2$ episodes/week and $\leq 2$ units of alcohol/week). Virtually all adolescents (95\%) had not taken cannabis or any other drug. Rates of criminal offending were low as well. Three adolescents had been arrested by the police, for violence, theft, and disrupting public order, respectively. The two treatment groups did not differ on any of these variables.

\section{Study flow}

Few adolescents and parents dropped out from the study between baseline and 6 months follow-up (Fig. 1). The 6months follow-up completion rate was $100 \%$ for the MDFT adolescents and parents and $86.7 \%$ for the FTAU groups (ns). The 12-months completion rate was $91.7 \%$ for the MDFT youth and $70.0 \%$ for the FTAU youth $\left(\chi^{2}=2.22 ; P\right.$ $=0.14)$. The corresponding 12-months figures for parents were $91.7 \%$ for MDFT and $80.0 \%$ for FTAU (ns).

Table 2. Baseline characteristics of the study sample

\begin{tabular}{|c|c|c|c|}
\hline Variable & $\begin{array}{l}\text { MDFT group } \\
(N=12)\end{array}$ & $\begin{array}{l}\text { FTAU group } \\
\quad(N=30)\end{array}$ & $\begin{array}{c}\text { Total } \\
(N=42)\end{array}$ \\
\hline Adolescent age & $14.9(2.7)$ & $14.9(1.8)$ & $14.9(2.0)$ \\
\hline Male gender & $91.7 \%$ & $100.0 \%$ & $97.6 \%$ \\
\hline $\begin{array}{l}\text { Adolescent born in } \\
\text { Switzerland }\end{array}$ & $75.0 \%$ & $73.3 \%$ & $73.8 \%$ \\
\hline Foreign descent ${ }^{\mathrm{a}}$ & $83.3 \%$ & $83.3 \%$ & $83.3 \%$ \\
\hline $\begin{array}{l}\text { Parents divorced/ } \\
\text { separated }\end{array}$ & $60.0 \%$ & $46.7 \%$ & $47.6 \%$ \\
\hline \multicolumn{4}{|l|}{$\begin{array}{l}\text { Primarily lives } \\
\text { with }^{\mathrm{b}}\end{array}$} \\
\hline Mother & $100.0 \%$ & $100.0 \%$ & $100.0 \%$ \\
\hline Father & $57.1 \%$ & $53.3 \%$ & $57.1 \%$ \\
\hline Other & $4.8 \%$ & $0 \%$ & $2.4 \%$ \\
\hline $\begin{array}{l}\text { Enrolled in school } \\
\text { School level }^{\mathrm{d}}\end{array}$ & $91.7 \%$ & $96.6 \%$ & $95.1 \%$ \\
\hline High & $9.1 \%$ & $25.0 \%$ & $20.5 \%$ \\
\hline Middle & $81.8 \%$ & $71.4 \%$ & $74.4 \%$ \\
\hline Low & $0 \%$ & $0 \%$ & $0 \%$ \\
\hline Other & $9.1 \%$ & $3.6 \%$ & $5.2 \%$ \\
\hline
\end{tabular}

The figures given for age are reported as averages: mean years (SD). ${ }^{a}$ Applies if at least one parent was born abroad.

${ }^{\mathrm{b}}$ More than one response possible.

${ }^{c}$ One FTAU youth missing school enrolment data (Total $n=41$ ).

${ }^{\mathrm{d}}$ As percentage of those enrolled. High $=$ high-level secondary school. Middle $=$ middle-level secondary school. Low $=$ lowerlevel secondary school. Other $=$ University or special school.
Adolescents who completed the 12-month follow-up $(n=32)$ were similar to non-completers $(n=10)$ in age $(t[40]=0.51, P=0.62)$ and number of IGD symptoms at baseline $(t[40]=-0.74, P=0.46)$.

\section{Gaming-related outcomes}

IGD diagnosis and criteria. At baseline, all adolescents presented with IGD. The average number of DSM- 5 criteria met was $6.7(S D=1.0)$. As Fig. 2 shows, the number of IGD criteria dropped between baseline and 6 months in both treatment groups but most strongly in the MDFT group (MDFT: $83.3 \%$ decrease vs. FTAU: 60.3\%; significant MDFT vs. FTAU difference in symptom count at 6 months: $t$ [36] $=$ $3.26, P<0.01$, Cohen's $d=1.23)$. The drop in number of IGD criteria met was maintained at 12 months (MDFT: 87.9\% decrease from baseline vs. FTAU: 63.3\%; significant MDFT vs. FTAU difference in symptom count at 12 months: $t[29.13]=2.81, P<0.01$, Cohen's $d=0.93)$. The reduction over time in number of IGD criteria met and the stronger treatment effect of MDFT over time were confirmed in an analysis of variance (time: $F[2,60]=$ 136.31, $P<0.001, \eta_{p}{ }^{2}=0.82$; treatment: $F[1,30]=8.56, P<$ $0.01, \eta_{p}{ }^{2}=0.22$; time $\mathrm{x}$ treatment: $F[2,60]: 2.83$, ns, $\eta_{p}{ }^{2}=$ 0.09 ). MI results produced an average $F$ statistic of 160.35 for time, 8.88 for treatment, and 2.66 for time by treatment.

At 6 and 12 months, none of the MDFT adolescents presented with IGD. Three FTAU adolescents still had IGD at 6 months (11.5\%) and four at 12 months (19.0\%). In neither case, FTAU significantly differed from MDFT. At 6 months, 5 MDFT adolescents (41.7\%) were free of all 9 IGD symptoms. This was true of 2 FTAU adolescents $(7.7 \%$; MDFT vs. FTAU, Fisher's Exact Test, $P<0.05)$. The corresponding figures for 12 months follow-up were: $6 \mathrm{MDFT}$ youth $(54.5 \%)$ symptom-free versus 5 FTAU youth $(23.8 \%$; $P=0.12)$.

Table 3 shows how often individual IGD criteria were endorsed at the three assessments. The criteria most often met at baseline were 'Continue gaming despite problems' (97.6\% for the two groups together) and 'Reduce or stop

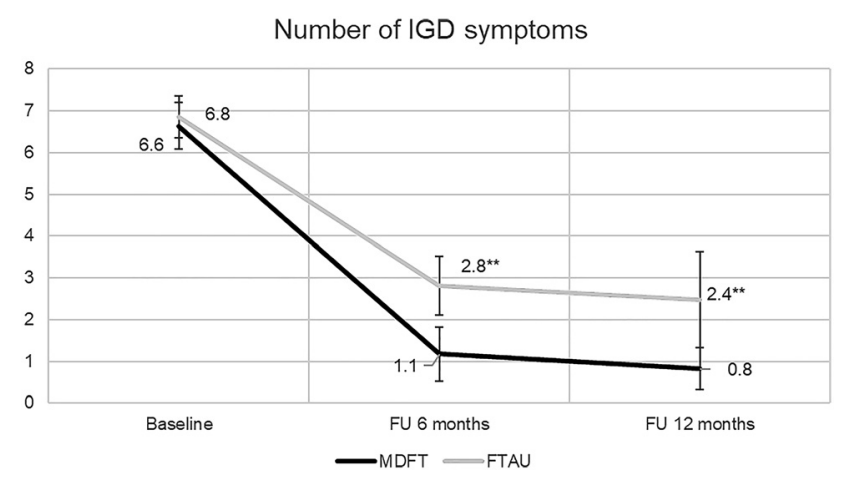

Fig. 2. The effect of treatment on the number of DSM-5 criteria met (out of a total of 9). MDFT = multidimensional family therapy. FTAU $=$ family therapy as usual. FU $=$ follow-up. ${ }^{* *} P<0.01$, MDFT vs. FTAU at the assessment noted 
Table 3. Prevalence of meeting individual DSM-5 IGD criteria

\begin{tabular}{|c|c|c|c|}
\hline \multirow[b]{2}{*}{ Criterion } & \multicolumn{3}{|c|}{ Assessment } \\
\hline & Baseline & $\begin{array}{l}\text { Follow-up, } 6 \\
\text { months }\end{array}$ & $\begin{array}{l}\text { Follow-up, } \\
12 \text { months }\end{array}$ \\
\hline Preoccupation & $69.0 \%$ & $36.8 \%$ & $21.9 \%$ \\
\hline Withdrawal & $83.3 \%$ & $7.9 \%$ & $15.6 \%$ \\
\hline Tolerance & $66.7 \%$ & $23.7 \%$ & $15.6 \%$ \\
\hline Reduce/stop gaming & $90.5 \%$ & $37.8 \%$ & $31.3 \%$ \\
\hline Give up other activities & $74.4 \%$ & $15.8 \%$ & $18.8 \%$ \\
\hline $\begin{array}{l}\text { Continue gaming } \\
\text { despite problems }\end{array}$ & $97.6 \%$ & $34.2 \%$ & $37.5 \%$ \\
\hline Deceive/cover-up & $64.3 \%$ & $13.2 \%$ & $12.5 \%$ \\
\hline Escape adverse moods & $60.5 \%$ & $34.2 \%$ & $28.1 \%$ \\
\hline $\begin{array}{l}\text { Risk or lose } \\
\text { relationships/ } \\
\text { opportunities }\end{array}$ & $76.2 \%$ & $13.2 \%$ & $9.4 \%$ \\
\hline
\end{tabular}

The two treatment groups combined. The short-hand description of the criteria has been adopted from Griffiths et al. (2016). IGD = Internet Gaming Disorder.

gaming' (90.5\%). For each criterion, the prevalence of endorsing the item diminished between baseline and followup assessments. The largest drops were seen for 'Risk or lose relationships/opportunities' (87.7\% decrease between baseline and 12 months), 'Withdrawal' (81.3\%), and 'Deceive/ cover-up' (80.6\%). At the individual criterion level, there were no statistically significant differences between MDFT and FTAU except for the 'Continue gaming despite problems' criterion, which at 6 months was more often met by FTAU (46.2\%) than by MDFT youth (8.3\%) (Fisher's Exact Test, $P<0.05)$.

Time spent on gaming. At baseline, the average daily time spent on playing games according to the TLFB was $3.6 \mathrm{~h}$ (SD 2.0) across groups. At 6 months, less time was spent on gaming (2.6 h MDFT, $3.1 \mathrm{~h}$ FTAU, total: $3.0 \mathrm{~h}$ ), but at the 12-month assessment gaming time had returned to the initial level (3.6 and $3.3 \mathrm{~h}$ for MDFT and FTAU, respectively). There was no effect of treatment on gaming time (time: $F[1.27,35.68]=2.17$ ns; treatment: $F[1,28]=0.05$, ns; time $\mathrm{x}$ treatment: $F[1.27,35.68]=0.47, \mathrm{~ns})$. MI results yielded an average $F$ of 2.01 for time, 0.11 for treatment, and 0.75 for the time by treatment interaction.

Quality of life: the gaming domain. Judging from their ASC T-ASI scores, the adolescents were not very concerned about their gaming behaviour (Table 4). Averaged across all adolescents, the baseline mean Gaming section score was 0.95 $(S D=1.0)$, which equals "small problems". At the follow-up assessments, the adolescents' scores were even lower (at 12 months, MDFT: $60.9 \%$ down from baseline, and FTAU 41.2\%). Across groups, this decrease over time in Gaming section score was significant $(F[2,60]=4.36, P<0.05)$, with no difference noted between MDFT and FTAU. MI results yielded an average $F$ of 4.13 for this comparison, with accompanying averages of 0.98 for the treatment comparison across time and 0.43 for the time by treatment interaction.
Table 4. Gaming problem severity scores, from the perspective of the adolescents and the parents

\begin{tabular}{lccc}
\hline & \multicolumn{3}{c}{ Assessment } \\
\cline { 2 - 4 } Treatment & Baseline & $\begin{array}{c}\text { Follow-up, 6 } \\
\text { months }\end{array}$ & $\begin{array}{c}\text { Follow-up, 12 } \\
\text { months }\end{array}$ \\
\hline \multicolumn{2}{l}{ View adolescents } & & \\
MDFT & $0.92(1.08)$ & $0.50(0.52)$ & $0.36(0.51)$ \\
FTAU & $0.97(1.00)$ & $0.85(0.83)$ & $0.57(0.68)$ \\
View parents & $3.08(1.00)$ & $2.58(1.17)$ & $1.64(1.21)$ \\
MDFT & $3.07(0.98)$ & $1.81(1.10)$ & $1.96(1.37)$ \\
FTAU & & &
\end{tabular}

Average score on a 5-point scale (Gaming section, ASC T-ASI Quality of Life scale), running from 0 (no problems) to 4 (very big problems). Between brackets: standard deviation. MDFT $=$ multidimensional family therapy. FTAU $=$ family therapy as usual.

The parents held another view. The average Gaming section score of the parents at baseline was 3.1, which equals "big problems" (Table 4). At follow-up, the parents' worries had abated (at 12 months, MDFT: $46.8 \%$ down from baseline, and FTAU 36.2\%). The trend over time was significant $(F[2,66]=15.87, P<0.001)$; the treatment groups did not differ on this measure. Corresponding MI averaged results were $F$ statistics of 17.62 for time, 0.35 for treatment, and 2.88 for time by treatment.

The discrepancy in gaming problems severity ratings between parents and adolescents diminished over time. Across groups at baseline, the average gap in scores was 2.1 points $(S D=1.2)$, versus 1.3 points at 12 months $(S D=1.3$; decrease in score discrepancy over time: $F[2,60]=5.04, P<0.01$; no difference between treatment groups). Respectively, averaged MI $F$ statistics were 5.67 for time, 1.00 for treatment, and 2.88 for time by treatment.

\section{Treatment retention and treatment dose}

As judged by the therapist, treatment was completed as planned in $100 \%$ of the MDFT cases and in $70 \%$ of FTAU cases (Fisher's Exact Test, $P<0.05$ ). Seven of the 9 FTAU non-completed treatment cases dropped out of therapy because of dissatisfaction with the treatment or therapist.

More sessions were held in MDFT than in FTAU (Table $5 ; t[25.11]=3.17, P<0.01$ ). This was due to a larger number of parent $(t[40]=2.40, P<0.05)$ and especially family sessions $(t[40]=3.66, P<0.01)$ in MDFT. There was no difference in number of adolescent sessions. Among treatment completers, only the number of family sessions differed between the MDFT $(M=8.1 ; S D=2.4)$ and FTAU groups $(M=5.8 ; S D=2.4)(t[31]=2.66, P<0.05)$. Duration of therapy sessions ranged from 45 to $90 \mathrm{~min}$. On average, MDFT sessions lasted longer than FTAU sessions (Table $5 ; t[40]=3.58, P<0.01$ ). This was due to the longer duration of the parent $(t[40]=2.60, P<0.05)$ and family $(t[40]=5.22, P<0.001)$ sessions, respectively. The duration of the adolescent sessions did not differ between the treatment groups $(t[25.11]=0.41, \mathrm{~ns})$. 
Table 5. Number of treatment sessions delivered

\begin{tabular}{lccc}
\hline & \multicolumn{3}{c}{ Treatment } \\
\cline { 2 - 4 } Type of session & MDFT $(n=12)^{\mathrm{a}}$ & FTAU $(n=30)^{\mathrm{a}}$ & Total $(n=42)$ \\
\hline Number with adolescent alone & $7.42(4.56)$ & $5.93(4.21)$ & $6.36(4.31)$ \\
Average duration of sessions (minutes) & $53.09(15.23)$ & $50.78(17.02)$ & $51.44(16.38)$ \\
Number with parents alone & $10.83(4.90)$ & $6.70(5.09)^{\star}$ & $7.88(5.33)$ \\
Average duration of sessions (minutes) & $72.01(15.10)$ & $58.39(15.41)^{\star}$ & $62.28(16.37)$ \\
Number with family (adolescent and & $8.08(2.43)$ & $4.87(2.62)^{\star *}$ & $5.79(2.94)$ \\
$\quad$ parents) & $85.82(6.83)$ & $65.37(12.80)^{\star * *}$ & $71.21(14.69)$ \\
Average duration of sessions (minutes) & $26.33(7.60)$ & $17.50(9.42)^{\star *}$ & $20.02(9.73)$ \\
Total number of sessions & $72.31(8.59)$ & $61.73(8.69)^{\star *}$ & $64.75(9.83)$ \\
Average duration of sessions (minutes) & $1,878.33(482.69)$ & $1,038.50(545.42)^{\star * *}$ & $1,278.45(648.37)$ \\
Total duration of sessions (minutes) & &
\end{tabular}

MDFT $=$ multidimensional family therapy. FTAU $=$ family therapy as usual. Between brackets, under the heading Treatment: standard deviation. Compared with MDFT, ${ }^{\star} P<0.05 ;{ }^{\star *} P<0.01$, ${ }^{\star * \star} P<0.001$, t-test.

${ }^{\text {a }}$ Full sample, including the participants who did not complete the treatment. When the latter cases were excluded from the analyses, the pattern of statistical differences remained the same.

We then inspected the number of treatment sessions and total treatment duration (i.e., minutes in all session types) as potential covariates. Number of family sessions was the only session type/duration variable that correlated with IGD symptoms post-baseline (i.e., at 12-months; $r=-0.41, P<$ 0.05). Therefore, we reran the IGD criteria ANOVA with number of family treatment sessions included as a covariate. The main effects of time $(F[2,58]=12.496, P<0.001)$ and treatment type $(F[1,29]=2.154, P<0.05)$ remained significant in this updated model; however, the effect size of each factor was reduced by approximately half (time: $\eta_{p}{ }^{2}=$ 0.82 vs. 0.30 ; treatment: $\eta_{p}{ }^{2}=0.22$ vs. 0.13 ).

Of note, we also ran ANOVAs with age of the adolescent (14 or lower vs. 15 or higher) and extent of discrepancy in adolescent-parent gaming problem ratings as covariates. These covariates were not significantly associated with treatment outcomes.

\section{DISCUSSION}

\section{Study hypotheses}

The aim of this study was to test if family therapy is effective in treating adolescents with IGD. We compared multidimensional family therapy (MDFT), which is an evidencebased treatment for SUD and delinquency in youth, with family therapy as usual (FTAU). We hypothesized that, across one year, both treatments would decrease the number of IGD criteria met and the prevalence of IGD, with MDFT outperforming FTAU. The hypotheses were partially supported.

At the start of the trial, the adolescents met 6.7 out of the 9 IGD criteria. The total number of IGD criteria met decreased for both treatments from baseline to the 6-months assessment and remained low at 12 months. The drop was larger for MDFT than for FTAU. In both groups, all individual IGD criteria diminished in prevalence rate across the follow-up period.

At baseline, all adolescents presented with IGD. Over time, the prevalence of IGD diminished in both groups. At
12 months, none of the 11 MDFT adolescents and 4 of the 21 FTAU adolescents had IGD; this difference was not statistically significant, possibly due to the small sample size.

One might argue that the decrease in IGD prevalence reflected spontaneous remission rather than a treatment effect. There is insufficient support for this argument. Spontaneous remissions - return of the adolescent, irrespective of treatment, to a non-problematic way of gaming does occur in IGD. In two longitudinal studies, with assessments spaced one year apart, the remission rate was $41 \%$ (Wartberg, Kriston, Zieglmeier, Lincoln, \& Kammerl, 2019) and even 72\% (Wartberg \& Lindenberg, 2020), which is sizable but not as large as the drops of $81 \%$ (FTAU) and $100 \%$ (MDFT) we noted in the present trial. A comparison between investigations is difficult, though. The samples of adolescents in the longitudinal studies cited were non-clinical and at least half of the youth were female.

\section{Time spent on gaming}

There was no effect of treatment on time spent gaming. However, the amount of self-reported gaming was rather low among the study participants compared to other adolescent clinical samples (Kim, Han, Lee, \& Renshaw, 2012; Sakuma et al., 2017). Conceivably, this might have been due to a measurement problem. The TLFB, a frequency of use calendar method with strong credentials in the substance use research field, may be less adequate for gaming studies. If parents confiscate gaming paraphernalia or impose other gaming restrictions, this may lead to erroneously low estimates of the time engaged in gaming averaged across days. Also, the adolescents in our study may have strategically underreported the time spent on gaming to contradict the parents' views of their child's gaming problems. A second issue to consider here is that adolescents can engage in gaming for a substantial amount of time without necessarily becoming problematic gamers (Peeters et al., 2019). Conversely, spending much time on gaming need not be an essential feature of IGD (Milani et al., 2018). At any rate, the time spent on gaming data should not be taken to 
suggest that our study samples were mildly impaired and therefore easy to treat. In fact, a consensus emerged amongst MDFT and FTAU therapists that IGD adolescents were at least as hard to treat as SUD adolescents.

\section{Gaming-related quality of life}

According to the quality of life data gathered, the adolescents were not very worried about their gaming problems, which they rated as "small" on average. This low score dropped even more from baseline to follow-up assessments, indicating that treatment had effect on perception of problem severity. In contrast, the parents rated their child's gaming problems as "big". This discrepancy in judgment is of key clinical importance. It underscores that therapy should not be limited to treating the adolescent. Family relationships need to be considered as well.

The discrepancy in how gaming problems were viewed by the adolescents compared to their parents grew smaller between baseline and follow-up assessments, suggesting that treatment - both MDFT and FTAU - helped to bridge gaps between youth and parents.

\section{Reasons for offering family therapy}

IGD in adolescents is associated with social variables including parental and family factors (Nielsen et al., 2019, 2020), as is also suggested by some of our present findings. For instance, three-quarters of all adolescents met the IGD criterion 'Risk or lose relationships/opportunities', which includes family relationships. At 12 months, only $9.4 \%$ of the youth met this criterion, the lowest percentage across the board of IGD criteria.

It has been argued that parental, family and other social factors (e.g., school-related) should be addressed in IGD therapies, in addition to intra-individual characteristics of the adolescent (Bonnaire et al., 2019, 2020; Zajac et al., 2020). This multidimensional focus is a major difference between MDFT and FTAU. In addition to individual level interventions with the adolescent and parent(s), MDFT emphasizes enhancement of emotional bonds. Harsh and rejecting relationships within a family may encourage more gaming; just as problematic gaming jeopardizes relationships. The treatment's goal is to have the family unit move away from a pathologizing reading of the gaming behaviour of the youth. The MDFT therapist's aim is to reconnect the adolescent and his or her parents. If reconnection succeeds, the teen may be more responsive to parental rules and regulations and the parents will act in a less hostile and angry way.

The superiority of MDFT over FTAU was not due to MDFT offering more sessions. When treatment intensity was added as covariate in the analyses, the differential treatment effects remained intact. The only treatment variable linked to significance level was the number of family sessions.

\section{Limits and strengths of the study}

The main limitation of this study was the small sample size. We recruited 42 adolescents rather than the 60 planned.
There are various reasons why recruitment fell short. At present, parents, schools and mental health and youth care centres are still largely unaware of the available IGD treatment options. The trial was also hindered by policy changes the Phénix Foundation felt forced to make. At the end of our trial the family therapy unit of Phénix was restructured.

Unfortunately, we had no funds to videotape a sufficient number of FTAU sessions and analyse them for treatment integrity as we did for MDFT. At issue here is if FTAU and MDFT are distinct treatments, with no contamination of FTAU by MDFT. The first author reviewed the FTAU sessions that were recorded and found no signs of such contamination. All MDFT and FTAU therapists completed and submitted weekly reports of the number and nature of sessions. Reviewing these materials, we again found no sign of FTAU being contaminated by MDFT. However, the materials mentioned do not lend themselves to quantitative analyses, so we cannot conclude with certainty that MDFT and FTAU were distinct.

The strength of the study was its design, a randomised controlled trial meeting CONSORT quality criteria gathering information from two sources: the adolescents and their parents.

We examined two forms of locally available family therapy rather than comparing family therapy with a waiting list control group. Trials with waiting list control conditions may overestimate treatment effects. Apparently, by telling people to wait for treatment, they lose momentum; they do not move forward to action on their own (Cunningham, Kypri, \& McCambridge, 2013). Often, being placed on a waiting list does not work as a placebo - it does not necessarily generate positive expectations among the people concerned - but rather as a nocebo (Steinert, Stadter, Stark, \& Leichsenring, 2017). Comparing a treatment with a nocebo increases the chance of 'finding' a treatment effect. Apart from these considerations and at a more practical level, we believe that treatment motivation would have dwindled if we had offered therapy-shy adolescents an 'escape' by placing them on a waiting list.

Comparing a new treatment (MDFT) with an established treatment (FTAU) adds to the clinical relevance of the findings: the new therapy is not only effective, but also more effective than currently available therapy. However, MDFT is an intensive treatment and therefore will cost more than briefer treatments. As treatment for SUD and delinquency, MDFT has been shown to be cost-effective when pitched against CBT. MDFT's higher gains in health and quality of life outweigh its higher costs (Goorden et al., 2016). The cost-effectiveness of MDFT as an IGD treatment is yet to be established.

\section{CONCLUSIONS}

In this study, the first randomised controlled trial of family therapy in adolescent IGD, therapy lowered the prevalence of IGD and decreased the number of IGD criteria met. On the latter measure, MDFT was more effective than FTAU. 
The size of the trial was small. The study needs to be replicated at a larger scale.

Funding sources: This study was supported by Action Innocence (actioninnocence.org), a non-profit agency promoting children's dignity and integrity on the Internet, Loterie Suisse Romande, and the private charities Divesa, André \& Cyprien, Hans Wilsdorf, and Isabelle Hafen. The funding agencies had no influence on the work reported here.

Authors' contributions: PN and HR conceived the study and jointly coordinated the research activities. $\mathrm{MC}$ and $\mathrm{CH}$ analysed the data. HL consulted on the ongoing clinical work, and guided adaption of MDFT for treating adolescents with gaming problems. MCK carried the medical and legal responsibility of the study, acquired the funds needed and was instrumental in setting up the research infrastructure in the Phénix-Mail treatment centre. NF contributed to the interpretation of the results. All authors were involved in drafting the present paper and in revising it critically for important intellectual content. All authors take responsibility for the content of this paper and agree to be accountable for all aspects of the work reported.

Conflict of interest: The authors declare no conflict of interest.

Acknowledgements: We thank Merryl Schoepf, Alessia Renevey and Aurore Hertz for collecting the data, Sandra Privet for recruitment and planning, and the FTAU and MDFT therapists (Christine Merino, Sabrina Cappuccio, Aviva Veron-Bourezg, Veronica Rato, Eva Cardenoso-Wark and Cecilia Soria) for delivering the treatments. MDFT supervisors Céline Bonnaire and Olivier Phan (Pierre Nicole Centre, Croix-Rouge Française, Paris; and Clinique Dupré, Sceaux, France) contributed to the adaptation of MDFT for IGD treatment purposes.

\section{REFERENCES}

APA. (2013). Diagnostic and statistical manual of mental disorders (5th ed.).

Baldwin, S. A., Christian, S., Berkeljon, A., \& Shadish, W. R. (2012). The effects of family therapies for adolescent delinquency and substance abuse: A meta-analysis. Journal of Marital and Family Therapy, 38(1), 281-304. https://doi.org/10.1111/j.17520606.2011.00248.x.

Barrett, H., Slesnick, N., Brody, J., Turner, C., \& Peterson, T. (2001). Treatment outcomes for adolescent substance abuse at 4-and 7-month assessments. Journal of Consulting and Clinical Psychology, 69(5), 802. https://doi.org/10.1037/0022-006X.69.5. 802.

Bonnaire, C., Liddle, H., Har, A., Nielsen, P., \& Phan, O. (2019). Why and how to include parents in the treatment of adolescents presenting internet gaming disorder? Journal of
Behavioral Addictions, 8(2), 201-212. https://doi.org/10.1556/ 2006.8.2019.27.

Bonnaire, C., Liddle, H., Har, A., \& Phan, O. (2020). Searching for change mechanisms in emotion-focused work with adolescents and parents: An example from multidimensional family therapy. Couple and Family Psychology: Research and Practice, 9(2), 100. https://doi.org/10.1037/cfp0000136.

Cunningham, J. A., Kypri, K., \& McCambridge, J. (2013). Exploratory randomized controlled trial evaluating the impact of a waiting list control design. BMC Medical Research Methodology, 13(1), 150. https://doi.org/10.1186/1471-2288-13-150.

Davis, M. L., Powers, M. B., Handelsman, P., Medina, J. L., Zvolensky, M., \& Smits, J. A. (2015). Behavioral therapies for treatment-seeking cannabis users: A meta-analysis of randomized controlled trials. Evaluation \& The Health Professions, 38(1), 94-114. https://doi.org/10.1177/0163278714529970.

Goorden, M., van der Schee, E., Hendriks, V. M., \& Hakkaart-van Roijen, L. (2016). Cost-effectiveness of multidimensional family therapy compared to cognitive behavioral therapy for adolescents with a cannabis use disorder: Data from a randomized controlled trial. Drug and Alcohol Dependence, 162, 154-161. https://doi.org/10.1016/j.drugalcdep.2016.03.004.

Griffiths, M. D., van Rooij, A. J., Kardefelt-Winther, D., Starcevic, V., Kiraly, O., Pallesen, S., et al. (2016). Working towards an international consensus on criteria for assessing internet gaming disorder: A critical commentary on Petry et al. (2014). Addiction, 111(1), 167-175. https://doi.org/10.1111/add.13057.

Han, D. H., Kim, S. M., Lee, Y. S., \& Renshaw, P. F. (2012). The effect of family therapy on the changes in the severity of on-line game play and brain activity in adolescents with on-line game addiction. Psychiatry Research: Neuroimaging, 202(2), 126-131. https://doi.org/10.1016/j.pscychresns.2012.02.011.

Kim, S. M., Han, D. H., Lee, Y. S., \& Renshaw, P. F. (2012). Combined cognitive behavioral therapy and bupropion for the treatment of problematic on-line game play in adolescents with major depressive disorder. Computers in Human Behavior, 28(5), 1954-1959. https://doi.org/10.1016/j.chb.2012.05.015.

King, D. L., Chamberlain, S. R., Carragher, N., Billieux, J., Stein, D., Mueller, K., et al. (2020). Screening and assessment tools for gaming disorder: A comprehensive systematic review. Clinical Psychology Review, 77, 101831. https://doi.org/10.1016/j.cpr. 2020.101831.

King, D. L., Delfabbro, P. H., Wu, A. M. S., Doh, Y. Y., Kuss, D. J., Pallesen, S., et al. (2017). Treatment of internet gaming disorder: An international systematic review and CONSORT evaluation. Clinical Psychology Review, 54, 123-133. https://doi.org/ 10.1016/j.cpr.2017.04.002.

King, D. L., Wolfling, K., \& Potenza, M. N. (2020). Taking gaming disorder treatment to the next level. JAMA Psychiatry, 77(8), 869-870. https://doi.org/10.1001/jamapsychiatry. 2020.1270 .

Liddle, H. (2002). Multidimensional family therapy for adolescent cannabis users. Cannabis Youth treatment (CYT) series, volume 5D. HHS Pub. No. 02-3660 Rockville, MD: Center for Substance Abuse Treatment, Substance Abuse and Mental Health Services Administration. Download available at http://www. mdft.org/mdft/media/files/Publications/MDFT-(2002)-CYT_ Manual.pdf. 
Liddle, H. (2016). Multidimensional family therapy: Evidence base for transdiagnostic treatment outcomes, change mechanisms, and implementation in community settings. Family Process, 55(3), 558-576. https://doi.org/10.1111/famp.12243.

Liddle, H., \& Rigter, H. (2013). How developmental research and contextual theory drive clinical work with adolescents with addiction. Harvard Review of Psychiatry, 21(4), 200-204. https://doi.org/10.1097/HRP.0b013e31829aaa6b.

Milani, L., La Torre, G., Fiore, M., Grumi, S., Gentile, D., Ferrante, M., et al. (2018). Internet gaming addiction in adolescence: Risk factors and maladjustment correlates. International Journal of Mental Health and Addiction, 16(4), 888-904. https://doi.org/ 10.1007/s11469-017-9750-2.

Nielsen, P., Favez, N., Liddle, H., \& Rigter, H. (2019). Linking parental mediation practices to adolescents' problematic online screen use: A systematic literature review. Journal of Behavioral Addictions, 8(4), 649-663. https://doi.org/10.1556/2006.8.2019.61.

Nielsen, P., Favez, N., \& Rigter, H. (2020). Parental and family factors associated with problematic gaming and problematic internet use in adolescents: A systematic literature review. Current Addiction Reports, 1-22. https://doi.org/10.1007/ s40429-020-00320-0.

Peeters, M., Koning, I., Lemmens, J., \& van den Eijnden, R. (2019). Normative, passionate, or problematic? Identification of adolescent gamer subtypes over time. Journal of Behavioral Addictions, 8(3), 574-585. https://doi.org/10.1556/2006.8.2019.55.

Petry, N. M., Rehbein, F., Gentile, D., Lemmens, J., Rumpf, H. J., Mößle, T., et al. (2014). An international consensus for assessing internet gaming disorder using the new DSM-5 approach. Addiction, 109(9), 1399-1406. https://doi.org/10. 1111/add.12457.

van der Pol, T. M., Hoeve, M., Noom, M. J., Stams, G., Doreleijers, T. A. H., van Domburgh, L., et al. (2017). Research Review: The effectiveness of multidimensional family therapy in treating adolescents with multiple behavior problems - A meta-analysis. Journal of Child Psychology and Psychiatry, 58(5), 532-545. https://doi.org/10.1111/jcpp.12685.

Reckers-Droog, V., Goorden, M., Kaminer, Y., van Domburgh, L., Brouwer, W., \& Hakkaart-van Roijen, L. (2020). Presentation and validation of the Abbreviated Self Completion TeenAddiction Severity Index (ASC T-ASI): A preference-based measure for use in health-economic evaluations. PloS One, 15(9), e0238858.

Rigter, H., Henderson, C. E., Pelc, I., Tossmann, P., Phan, O., Hendriks, V., et al. (2013). Multidimensional family therapy lowers the rate of cannabis dependence in adolescents: A randomised controlled trial in Western European outpatient settings. Drug and Alcohol Dependence, 130(1-3), 85-93. https://doi.org/10.1016/j.drugalcdep.2012.10.013.

Rigter, H., Pelc, I., Tossmann, P., Phan, O., Grichting, E., Hendriks, V., et al. (2010). INCANT: A transnational randomized trial of multidimensional family therapy versus treatment as usual for adolescents with cannabis use disorder. BMC Psychiatry, 10(1), 28. https://doi.org/10.1186/1471-244X-10-28.
Robinson, S., Sobell, L., Sobell, M., \& Leo, G. (2014). Reliability of the Timeline Followback for cocaine, cannabis, and cigarette use. Psychology of Addictive Behaviors, 28(1), 154. https://doi. org/10.1037/a0030992.

Rowe, C., Rigter, H., Henderson, C., Gantner, A., Mos, K., Nielsen, P., et al. (2013). Implementation fidelity of multidimensional family therapy in an international trial. Journal of Substance Abuse Treatment, 44(4), 391-399. https://doi.org/10.1016/j.jsat. 2012.08.225.

Sakuma, H., Mihara, S., Nakayama, H., Miura, K., Kitayuguchi, T., Maezono, M., et al. (2017). Treatment with the Self-Discovery Camp (SDiC) improves internet gaming disorder. Addictive Behaviors, 64, 357-362. https://doi.org/10.1016/j.addbeh.2016. 06.013 .

Sarda, E., Begue, L., Bry, C., \& Gentile, D. (2016). Internet gaming disorder and well-being: A scale validation. Cyberpsychology, Behavior, and Social Networking, 19(11), 674-679. https://doi. org/10.1089/cyber.2016.0286.

Schafer, J. L., \& Graham, J. W. (2002). Missing data: Our view of the state of the art. Psychological Methods, 7(2), 147-177. https://doi.org/10.1037/1082-989X.7.2.147.

Steinert, C., Stadter, K., Stark, R., \& Leichsenring, F. (2017). The effects of waiting for treatment: A meta-analysis of waitlist control groups in randomized controlled trials for social anxiety disorder. Clinical Psychology \& Psychotherapy, 24(3), 649-660. https://doi.org/10.1002/cpp.2032.

Stevens, M. W. R., King, D. L., Dorstyn, D., \& Delfabbro, P. H. (2019). Cognitive-behavioral therapy for internet gaming disorder: A systematic review and meta-analysis. Clinical Psychology \& Psychotherapy, 26(2), 191-203. https://doi.org/10. 1002/cpp.2341.

Sugaya, N., Shirasaka, T., Takahashi, K., \& Kanda, H. (2019). Bio-psychosocial factors of children and adolescents with internet gaming disorder: A systematic review. BioPsychoSocial Medicine, 13(1), 3. https://doi.org/10.1186/ s13030-019-0144-5.

Wartberg, L., Kriston, L., Zieglmeier, M., Lincoln, T., \& Kammerl, R. (2019). A longitudinal study on psychosocial causes and consequences of internet gaming disorder in adolescence. Psychological Medicine, 49(2), 287-294. https://doi.org/10.1017/ S003329171800082X.

Wartberg, L., \& Lindenberg, K. (2020). Predictors of spontaneous remission of problematic internet use in adolescence: A oneyear follow-up study. International Journal of Environmental Research and Public Health, 17(2), 448. https://doi.org/10.3390/ ijerph17020448.

WHO. (2018). International classification of diseases for mortality and morbidity statistics (11th Revision). Retrieved from https:// icd.who.int/browse11/1-m/en\#/http://id.who.int/icd/entity/ 1448597234.

Zajac, K., Ginley, M. K., \& Chang, R. (2020). Treatments of internet gaming disorder: A systematic review of the evidence. Expert Review of Neurotherapeutics, 20(1), 85-93. https://doi.org/10. 1080/14737175.2020.1671824.

Open Access. This is an open-access article distributed under the terms of the Creative Commons Attribution-NonCommercial 4.0 International License (https:// creativecommons.org/licenses/by-nc/4.0/), which permits unrestricted use, distribution, and reproduction in any medium for non-commercial purposes, provided the original author and source are credited, a link to the CC License is provided, and changes - if any - are indicated. 